\title{
DESIGN, ANALYSIS \& OPTIMIZATION OF COMPLIANT MECHANISMS
}

\section{ROHAN S. KULKARNI \& KSHITIJ DWIVEDI}

Vishwakarma Institute of Technology, 666, Upper Indira Nagar, Bibwewadi, Pune, Maharashtra, India

\begin{abstract}
ABSTACT
The project revolves around how the compliant mechanisms are redefining the design of our products which we us in our day to day life. All these years we have been building our products by combining or joining separately manufactured components to make a single component that satisfies our purpose.

In this type of manufacturing we often compromise on efficiency and performance due to incapability, cost of manufacturing. The rise in the industry of additive manufacturing due to $3 D$ printing has a major contribution in helping the manufacturing of compliant mechanism. Compliant mechanisms gain some or all of their motion from the relative flexibility of their joints rather than rigid body only. Our project elaborates on how different materials affect the performance of the fully compliant plier like the force, stress, deformation, torque and their mathematical calculations are also shown. The topological path model and the finite element analysis carried out also speaks about how the mechanism will be better than the conventional plier.

KEYWORDS: Compliant Mechanisms, Efficiency, 3D Printing, Joints, Flexible-Link Mechanism, Finite Element Analysis
\end{abstract}

Received: Jun 08, 2020; Accepted: Jun 28, 2020; Published: Sep 14, 2020; Paper Id.: IJMPERDJUN20201205

\section{INTRODUCTION}

In a reciprocating engine, the linear input is transformed into an output rotation, and the input force is transformed to an output force. Considering vice grip, its mechanism transfers energy from your hand (input) to the gripper teeth (output).If friction losses are to be neglected we can say that the energy is conserved between the input and output, where the output might be much larger than the input force, at the same time displacement taking place at output is very small as compared to the displacement taking place at input. In most of the everyday things we use, we see that their structures mostly consist of rigid links which are connected at the joints and as a result, relative motion hardly takes place or does not take place between the links. The major difference between a structure and a mechanism is that structure does not offer mobility or a structure which is rigid cannot be termed as a mechanism. We are surrounded by mechanisms. Automobiles, sports equipment's, furniture, construction equipment's, robotics and almost anything that has mobility is an example of a mechanism.

Compliant mechanisms can be simply explained as mechanism with only a single link which has mobility. These mechanisms are developed in order to increase the efficiency and in general the performance of a product which is manufactured as a compliant mechanism. But due to manufacturing constraints like cost, material availability, availability of technology these kinds of mechanism are not seen in the market as a product. It will be just a matter of time until significant research is carried out and we will be using compliant mechanisms in our day to day life frequently. 


\section{LITERATURE REVIEW}

The authors of this paper went about with the literature search focused mainly on the topics related to the complaint mechanisms. Extensive research on compliant mechanisms and its design was carried out by the authors of the paper. The first step in the design of a compliant mechanism was to establish a kinematically functional design that generates the desired output motion when subjected to prescribed input forces. This is called topological synthesis. As the topology is determined, the shape and size of individual elements can only be optimized to a certain extent in this early stage of analysis. After the required topology is achieved, constraints which hamper the performance which are usually in the design domain can be worked upon. These constraints are mainly minimization of energy loss in the given mechanism, amplifying geometric advantages such as motion or mobility of links or amplifying mechanical advantages such as increasing the force output with decreasing the input and making the mechanism buckle free under applications of external loads or forces.

I.Her, A.Midha ${ }^{[1]}$ gives the basic concept of compliant mechanism, a compliance number and type of synthesis. The purpose of this paper is to identify and discuss some important kinematic properties of compliant mechanism. In this paper, degree of freedom concept for rigid mechanism is briefly explained. Synthesis of rigid mechanism depends upon mechanism type and number of links and joints, but synthesis of compliant mechanism depends upon instances (i.e. compliance of joints and links). Compliance content of a link, Degree of compliance concept is clearly explained with respect to rigid and elastic counterparts.

Even though the authors of this paper had carried out a vast and varied research with the help of going through some papers published on designing compliant mechanisms they also had some valuable inputs from Prof. G.D Korwar who is himself doing a $\mathrm{PhD}$ in compliant mechanisms. According to him the aim of the paper should be to determine the limits of mobility of different kinds of the compliant joints in order to aid in the design of the compliant mechanisms. This is exactly what the authors then tried to work. After some more research the authors then concluded that a single link or compliant mechanism with film joint has greater mobility than beam or notch joint. Compliant mechanism with silicone joints has greater mobility than plastic joints but compliant mechanism with plastic joint can be built in one piece is what was concluded.

\section{METHODOLOGY}

The authors of the paper went on to design a compliant plier using Solidworks. The dimensions of the plier were taken from STP file provided by BYU University. Ansys analysis of the plier was also performed by the authors for stress analysis and total deformation as these are the major factors that decide the life span of plier and gives more clarity about selection of material for manufacturing. Ansys analysis is done for four different kind of material and the based on the analysis authors have suggested one best suited material for 3-D printing of pliers. Four materials chosen by the authors are Polylactic Acid(PLA),Acrylonitrile Butadiene Styrene (ABS), Thermoplastic Polyrethane (TPU) and Polyethylene Terephthalate Glycol (PETG). A path Model diagram is also proposed by authors that actually helps to understand the energy transfer sequence within the plier. some theoretical design and formula for torque calculation is also given by the authors which they would be able to apply later practically. The following methodology is explained in details as below-

3.1 Designing of plier

3.2 Ansys analysis 
3.3 Torque calculations (force muscle calculation)

3.4 Topological path model of compliant plier

\subsection{Designing of Plier}

The gripper has been modelled according to the original dimensions on the SOLIDWORKS 19 software. The same model has been used for the analysis purpose.

Table 1: Properties of Plier

\begin{tabular}{|c|c|}
\hline \multicolumn{2}{|c|}{ PROPERTIES } \\
\hline Volume & $1.189 \mathrm{e}+005 \mathrm{~mm}^{3}$ \\
\hline Mass & $0.1403 \mathrm{~kg}$ \\
\hline Centroid X & $83.125 \mathrm{~mm}$ \\
\hline Centroid Y & $29.616 \mathrm{~mm}$ \\
\hline Centroid Z & $12.504 \mathrm{~mm}$ \\
\hline Moment of Inertia Ip1 & $185.72 \mathrm{~kg} \cdot \mathrm{mm}^{2}$ \\
\hline Moment of Inertia Ip2 & $339.9 \mathrm{~kg} \cdot \mathrm{mm}^{2}$ \\
\hline Moment of Inertia Ip3 & $511.04 \mathrm{~kg} \cdot \mathrm{mm}^{2}$ \\
\hline
\end{tabular}

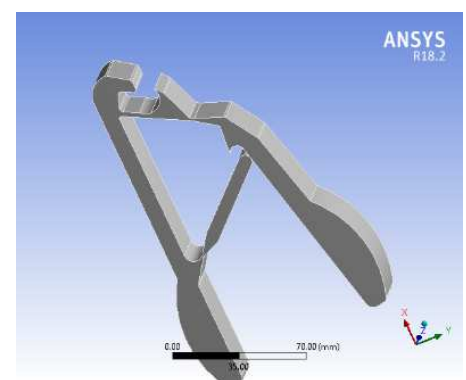

Figure 1: Cad model of complaint plier

\subsection{ANSYS Analysis}

Static structural Analysis is a branch of ANSYS that deals with numerical simulation methods and makes use of different algorithms to solve and analyze the problems that involves various kinds of forces. Static structural requires various settings like pressure, force, and various other factors.

\subsubsection{Properties Selection}

As the all the four materials chosen by authors are not available in the default library of ansys .so the author of the paper went on to read data sheets of various 3-D printing Companies and then calculated the average values and those same values are used for ansys analysis.

\subsubsection{Properties of All the Four Materials Taken for Analysis are as Follows}

Table 2: Properties of all the four materials

\begin{tabular}{|c|l|c|c|c|c|c|}
\hline SR.NO & PROPERTY & PLA & ABS & TPU & PETG & UNITS \\
\hline 1. & Density & $1.12 \mathrm{e}-006$ & $1.18 \mathrm{e}-006$ & $1.26 \mathrm{e}-006$ & $1.38 \mathrm{e}-006$ & $\mathrm{~kg} \mathrm{~mm}^{\wedge}-3$ \\
\hline 2. & $\begin{array}{l}\text { Tensile Yield } \\
\text { Strength }\end{array}$ & 35 & 38 & 42 & 45.8 & $\mathrm{MPa}$ \\
\hline 3. & $\begin{array}{l}\text { Tensile Ultimate } \\
\text { Strength }\end{array}$ & 41.83 & 44.8 & 48 & 53 & $\mathrm{MPa}$ \\
\hline
\end{tabular}




\begin{tabular}{|c|l|c|c|c|c|c|}
\hline 4. & $\begin{array}{l}\text { Young's } \\
\text { Modulus }\end{array}$ & 2700 & 2900 & 3100 & 3600 & $\mathrm{MPa}$ \\
\hline 5. & Poisson's Ratio & 0.35 & 0.35 & 0.3897 & 0.421 & - \\
\hline 6. & Bulk Modulus & 3000 & 3222.2 & 4684.2 & 7594.9 & $\mathrm{MPa}$ \\
\hline 7. & Shear Modulus & 1000 & 1074.1 & 1115.3 & 1266.7 & $\mathrm{MPa}$ \\
\hline 8. & $\begin{array}{l}\text { Compressive } \\
\text { Yield Strength }\end{array}$ & 40 & 42 & 46 & 55 & $\mathrm{MPa}$ \\
\hline
\end{tabular}

\subsubsection{Meshing}

The partial differential equations that govern fluid flow and heat transfer are not usually amenable to analytical solutions, except for very simple cases. Therefore, in order to analyze fluid flows, flow domains are split into smaller subdomains (made up of geometric primitives like hexahedra and tetrahedra in 3D and quadrilaterals and triangles in in 2D).The physical and mechanical properties required for the analysis were specified in the software. ANSYS software is based on Finite Element Analysis(FEA) method so it divides the model in small finite elements for analysis, this process is called as meshing. After the meshing, forces have been applied on the required surfaces. The magnitude and direction of the forces has been specified. Certain surfaces are given fixed constraints according to the placement of forces. Later the analysis was done for maximum equivalent stress and total deformation for all the four material.

\subsubsection{Properties of Meshing for Plier (Static Structural Analysis)}

Table 3: Meshing Details of compliant plier

\begin{tabular}{|c|c|}
\hline \multicolumn{2}{|c|}{ DISPLAY } \\
\hline Display Style & Body Color \\
\hline \multicolumn{2}{|c|}{ SIZING } \\
\hline Size Function & Adaptive \\
\hline Relevance Center & Fine \\
\hline Element Size & Default \\
\hline Mesh Defeaturing & Yes \\
\hline Defeature Size & Default \\
\hline Transition & Fast \\
\hline Initial Size Seed & Assembly \\
\hline Span Angle Center & Coarse \\
\hline Bounding Box Diagonal & $215.860 \mathrm{~mm}$ \\
\hline Minimum Edge Length & $9.5227 \mathrm{e}-002 \mathrm{~mm}$ \\
\hline \multicolumn{2}{|c|}{ STATISTICS } \\
\hline Nodes & 23728 \\
\hline Elements & 4344 \\
\hline
\end{tabular}

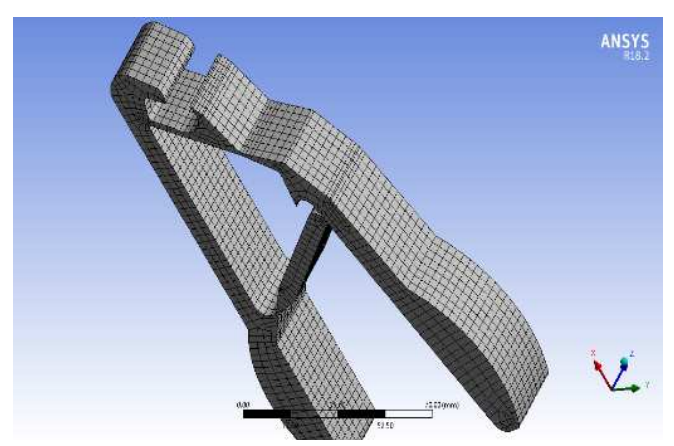

Figure 2: mesh model of plier 
NOTE-For all the four materials the meshing details are same as described above.

\subsubsection{Application of Force}

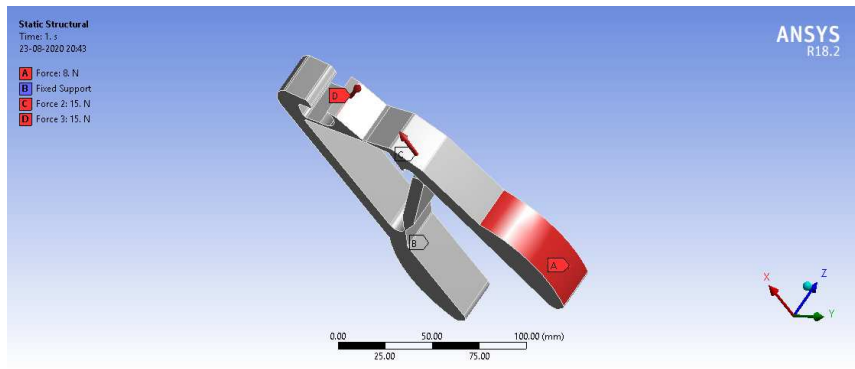

Figure 3: Application of forces

Table 4: Application of forces

\begin{tabular}{|c|c|c|c|c|}
\hline OBJECT NAME & FORCE & FIXED SUPPORT & FORCE 2 & FORCE 3 \\
\hline State & \multicolumn{4}{|c|}{ Fully Defined } \\
\hline \multicolumn{5}{|c|}{ SCOPE } \\
\hline Scoping Method & \multicolumn{4}{|c|}{ Geometry Selection } \\
\hline Geometry & \multicolumn{4}{|c|}{1 Face } \\
\hline \multicolumn{5}{|l|}{ DEFINITION } \\
\hline Type & Force & Fixed Support & \multicolumn{2}{|l|}{ Force } \\
\hline Define By & Vector & & \multicolumn{2}{|l|}{ Vector } \\
\hline Magnitude & 8. N (ramped) & & \multicolumn{2}{|c|}{ 15. N (ramped) } \\
\hline Direction & Defined & & \multicolumn{2}{|c|}{ Defined } \\
\hline Suppressed & \multicolumn{4}{|l|}{ No } \\
\hline
\end{tabular}

For all the four materials the application of force is at the same points and with same magnitude and direction so as to get a uniform result.

For taking various other readings the author of the paper have only altered one value of force i.e. force 1.

\subsubsection{Result Table for Maximum Stress}

Table 5: Result (maximum Stress)

\begin{tabular}{|c|c|c|c|c|c|c|c|}
\hline \multirow{2}{*}{ SR.NO } & \multicolumn{3}{|c|}{ FORCES(N) } & \multicolumn{4}{c|}{ STRESS(MPa) } \\
\cline { 2 - 7 } & FORCE 1 & FORCE 2 & FORCE 3 & PLA & ABS & TPU & PETG \\
\hline 1. & 6 & 15 & 15 & 55.387 & 55.00 & 54.612 & 53.897 \\
\hline 2. & 8 & 15 & 15 & 85.654 & 84.892 & 84.458 & 83.355 \\
\hline 3. & 10 & 15 & 15 & 115.93 & 115.230 & 114.31 & 112.82 \\
\hline 4. & 12 & 15 & 15 & 146.2 & 146.00 & 144.16 & 142.28 \\
\hline
\end{tabular}

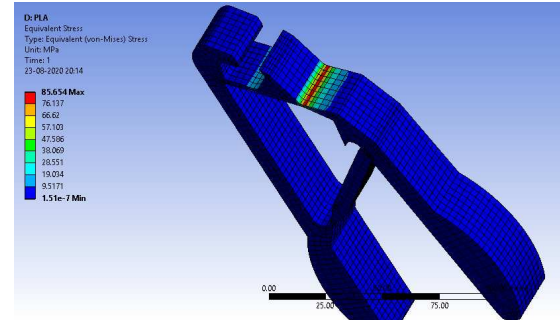

Figure 4: Stress analysis PLA Figure 5:Stress analysis ABS

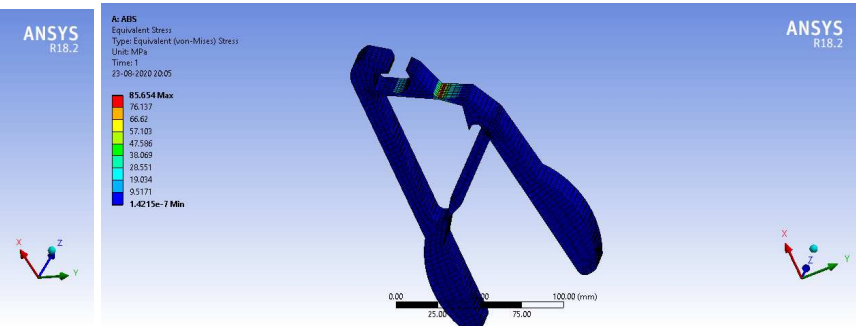




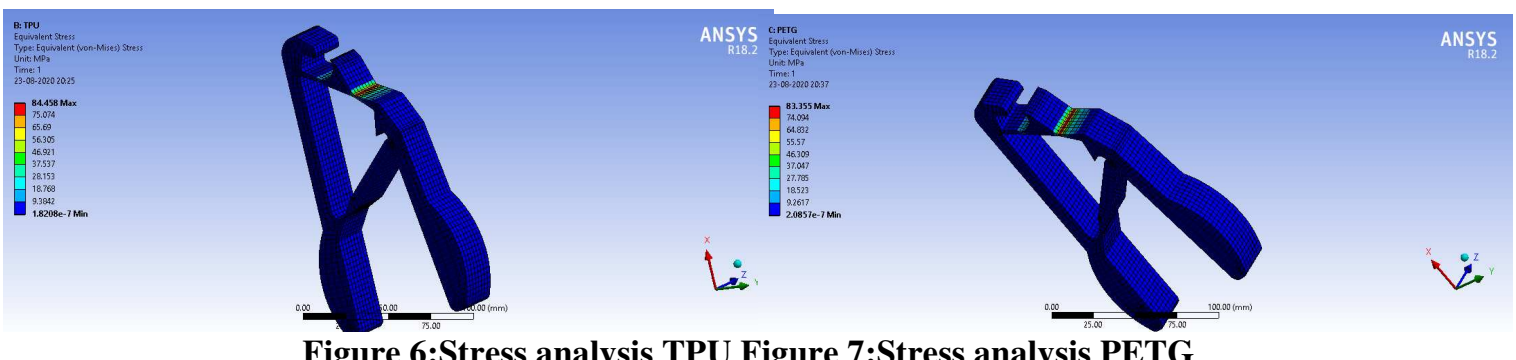

Figure 6:Stress analysis TPU Figure 7:Stress analysis PETG

\subsubsection{Result Table for Total Deformation}

Table 6: Result (Total Deformation)

\begin{tabular}{|c|c|c|c|c|c|c|c|}
\hline \multirow{2}{*}{ SR.NO } & \multicolumn{3}{|c|}{ FORCES(N) } & \multicolumn{4}{c|}{ DEFORMATION(mm) } \\
\cline { 2 - 8 } & FORCE 1 & FORCE 2 & FORCE 3 & PLA & ABS & TPU & PETG \\
\hline 1. & 6 & 15 & 15 & 22.695 & 21.13 & 19.29 & 16.255 \\
\hline 2. & 8 & 15 & 15 & 42.414 & 39.489 & 36.069 & 30.405 \\
\hline 3. & 10 & 15 & 15 & 62.143 & 57.857 & 52.856 & 44.563 \\
\hline 4. & 12 & 15 & 15 & 81.874 & 76.228 & 69.645 & 58.723 \\
\hline
\end{tabular}
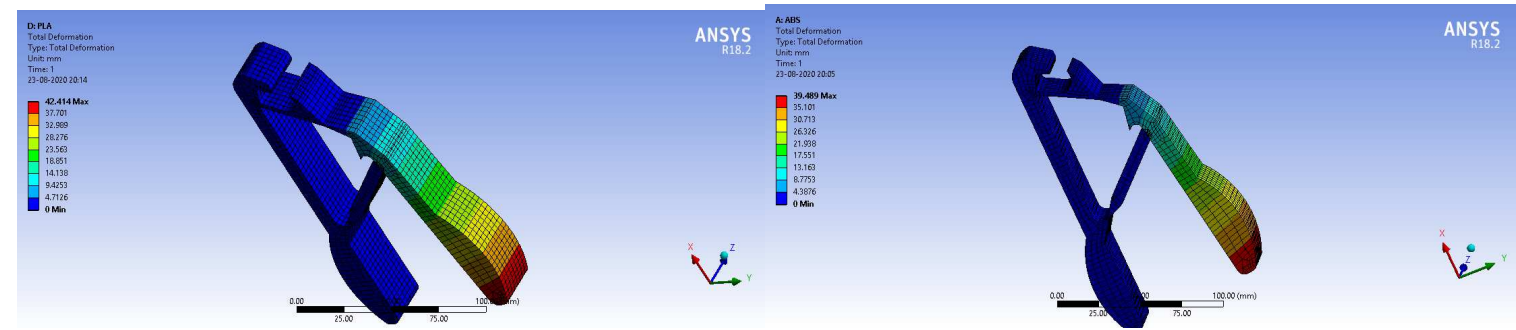

Figure 8: Total Deformation PLA Figure 9:Total Deformation ABS

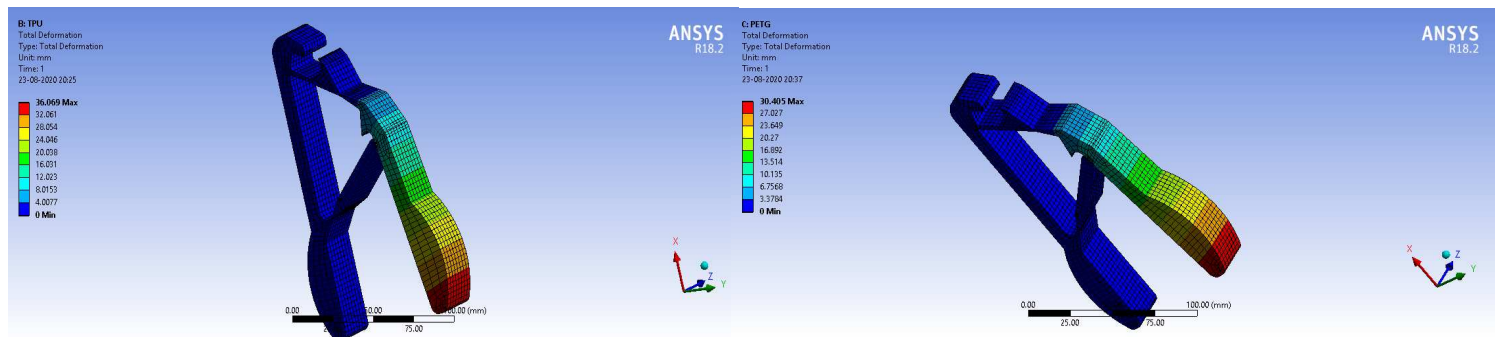

Figure 10: Total Deformation TPU Figure 11:Total Deformation PETG

3.2.7 Stress Comparison Graph for all the Four Material 


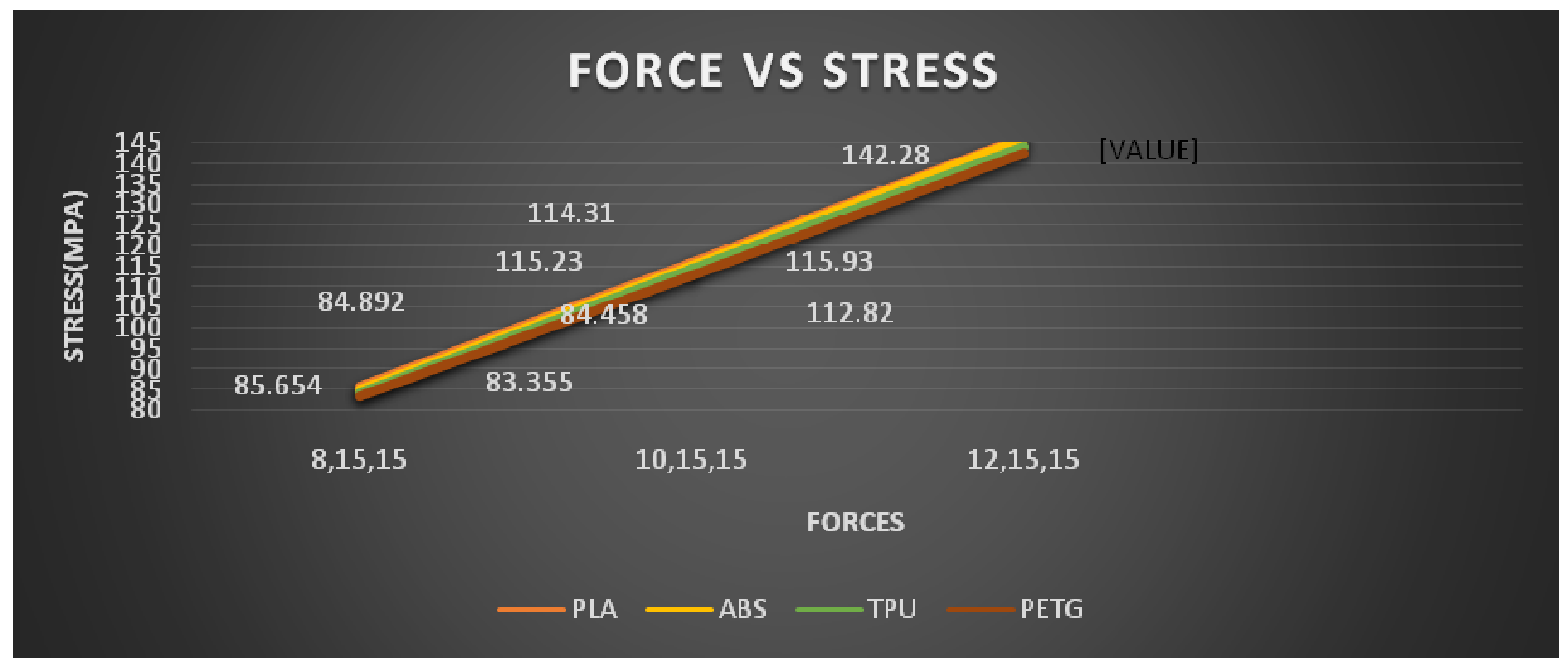

Figure 12: Graph (Stress VS Force)

3.2.8 Deformation Comparison for All the Four Material

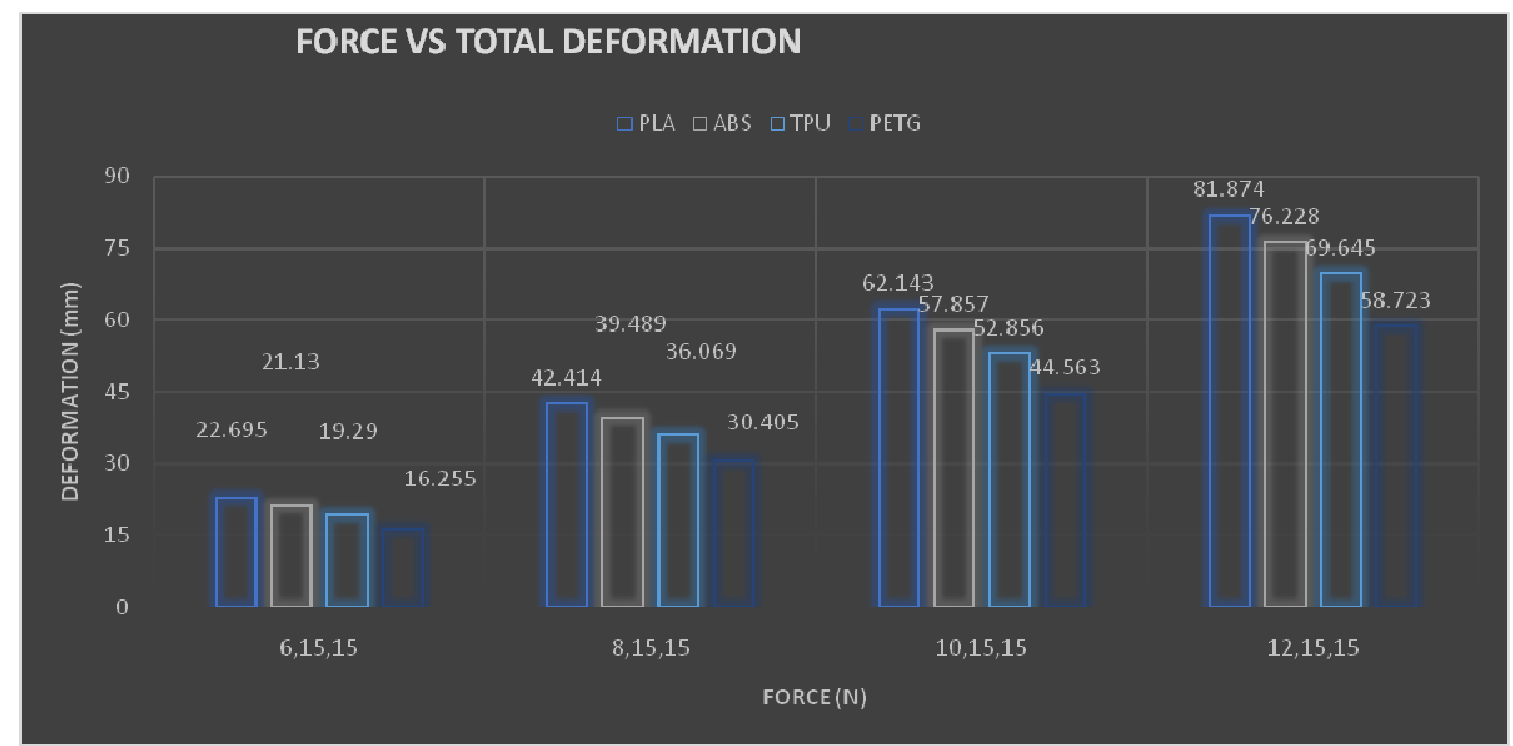

Figure 13: Graph (Force VS Total Deformation

\subsubsection{Force Muscle Calculation}

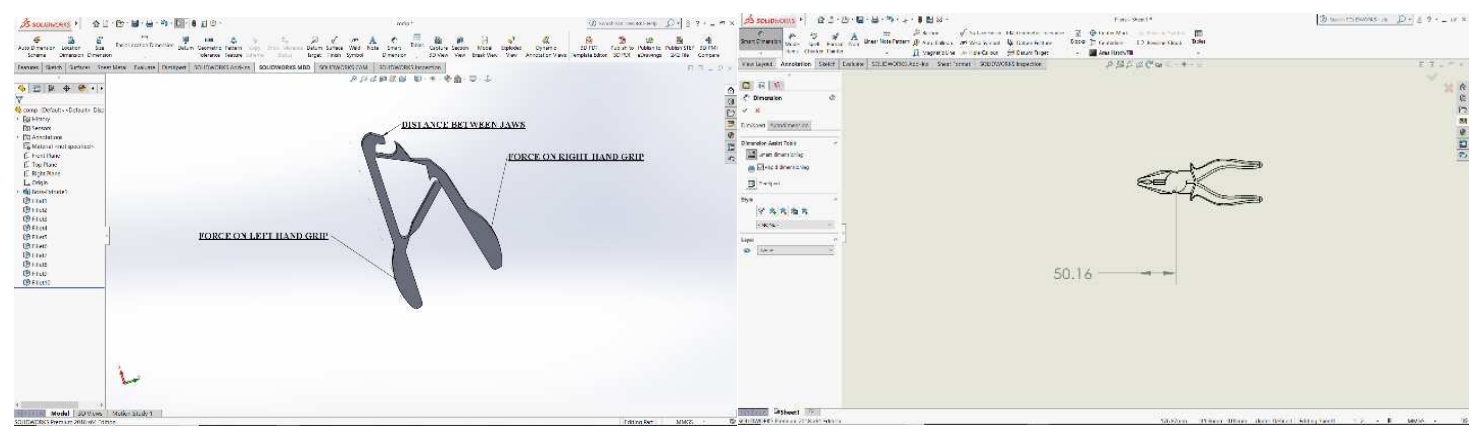

Figure 14: Torque Calculation

Figure 15 : Force muscle (Drafting)

Rivet- a point from where applied force on gripper passes on to output jaw. 
$\Sigma M$ about Rivet $=0$

F(L.HAND)*F(R.HAND)=F(CUTTING EDGES)*(MAX DISTANCE BETWEEN JAWS $)$

F(CUTTING EDGES $)=\quad$ F(L.HAND)*F(R.HAND)

(MAX DISTANCE BETWEEN JAWS)

As the system is in equilibrium about rivet .

as we can see max distance between jaws is less in complaint mechanisms so force output for same input will be more in case of Complaint mechanisms

For example - F(L.HAND $) * \mathbf{F}($ R.HAND $)=8 * 8(N)$

(MAX DISTANCE BETWEEN JAWS $)=1.89 \mathrm{~cm}($ for complaint $)$

$=2.5 \mathrm{~cm}($ for convectional $)$

F(CUTTING EDGES)complaint $=8 * 8 / 1.89=33.86 \mathrm{~N} / \mathrm{cm}$ (force of muscle)

F(CUTTING EDGES)convectional=8*8/2.5=25.6N/cm(force of muscle)

We can observe that for $8 \mathrm{~N}$ of force complaint mechanism gives more output.

\subsection{Torque Calculations}

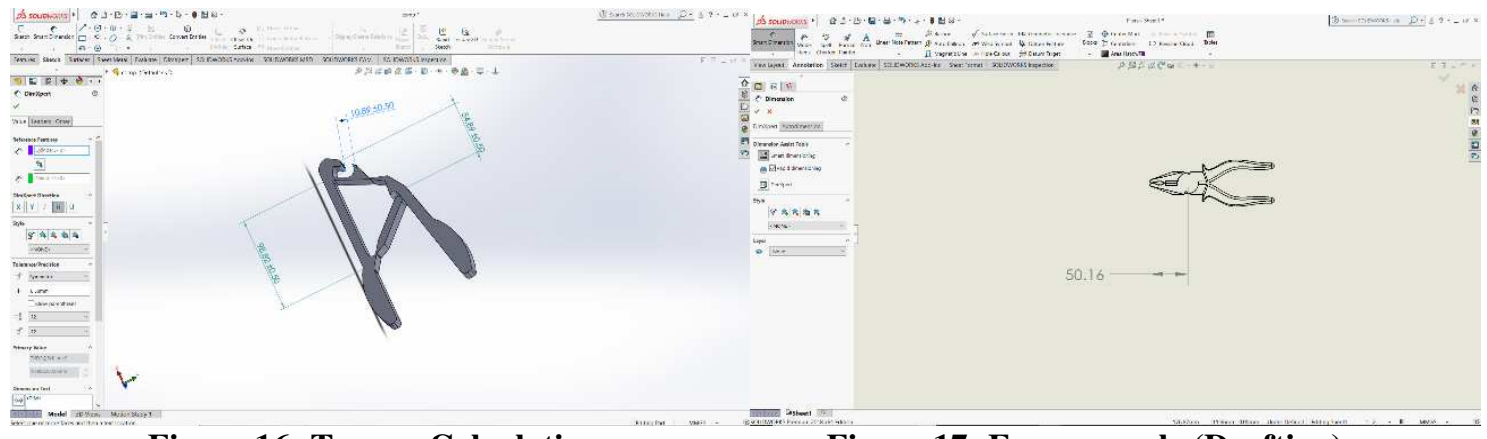

Figure 16: Torque Calculation

Figure 17: Force muscle (Drafting)

As we know that torque $=$ force $*$ perpendicular distance

As the perpendicular distance we'll take between one end of output jaw and to rivet.

Now as the distance $(r)=5.49 \mathrm{~cm}($ compliant $)$

$5.016 \mathrm{~cm}($ convectional)

$\mathrm{T}($ compliant $)=8 * 0.0549=0.4392 \mathrm{~N}-\mathrm{m}$

$T($ convectional $)=8 * 0.05016=0.40128 \mathrm{~N}-\mathrm{m}$

3.3.1 Result Table

Table 7: Result (Mathematical Calculations)

\begin{tabular}{|c|c|c|c|c|}
\hline Sr.no & $\begin{array}{c}\text { Property/calculated } \\
\text { value }\end{array}$ & $\begin{array}{c}\text { Convectional } \\
\text { mechanisms }\end{array}$ & $\begin{array}{c}\text { Compliant } \\
\text { mechanisms }\end{array}$ & $\begin{array}{c}\text { Percentage } \\
\text { increase in } \\
\text { complaint }\end{array}$ \\
\hline 1. & Muscle force (JAWS) & $25.6 \mathrm{~N} / \mathrm{cm}$ & $33.86 \mathrm{~N} / \mathrm{cm}$ & $24.39 \%$ \\
\hline 2. & TORQUE & $0.40128 \mathrm{~N}-\mathrm{m}$ & $0.4392 \mathrm{~N}-\mathrm{m}$ & $8.633 \%$ \\
\hline
\end{tabular}




\subsection{Topological Path Model Diagram}

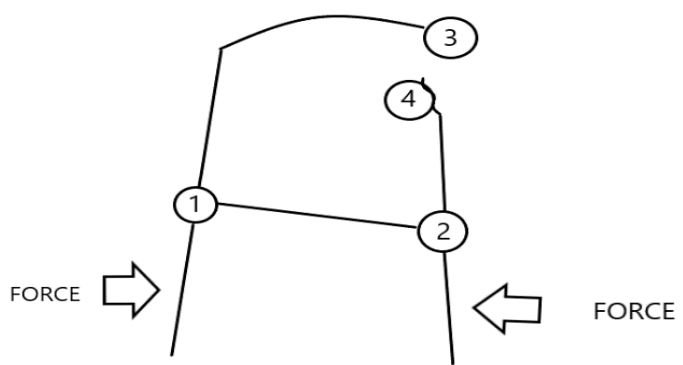

COMPLIANT PLIER

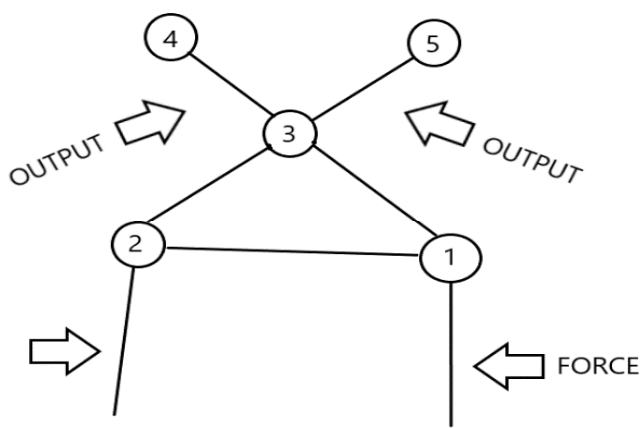

CONVENTIONAL PLIER

Figure 16: Topological path Model

Both the above figures show the topological path model diagram. Basically it shows the path which the applied force or input follows until it reaches output jaws. The force in compliant mechanism follows a simple path whereas path followed by input force in convectional plier is complex.

The authors suggest that this might be the reason why for same amount of input force convectional compliant mechanisms gives less output force as compared to compliant mechanism.

As in convectional plier it passes through many joints and as no joint converts $100 \%$ energy due to friction, so it gives less output.

Table 8: Topological sequence

\begin{tabular}{|c|l|c|c|}
\hline SR.NO & \multicolumn{1}{|c|}{$\begin{array}{c}\text { NAME OF } \\
\text { MECHANISMS }\end{array}$} & TOPOLOGICAL SEQUENCE & $\begin{array}{c}\text { NO OF } \\
\text { JOINTS }\end{array}$ \\
\hline \multirow{2}{*}{1.} & COMPLIANT & $(\mathrm{IN}) 1-2-4(\mathrm{OUT})$ & 1 \\
\cline { 3 - 4 } & & $(\mathrm{IN}) 1-2-3-4(\mathrm{OUT})$ & 1 \\
\hline 2. & CONVECTIONAL & $(\mathrm{IN}) 1-2-3-4(\mathrm{OUT})$ & 3 \\
\cline { 3 - 4 } & & $(\mathrm{IN}) 1-2-3-5(\mathrm{OUT})$ & 3 \\
\hline
\end{tabular}

\section{CONCLUSIONS}

In this project we have conducted a comparative analysis of different flexible materials used to make a fully compliant plier. This project has tried to convey that mechanisms that bend can also perform as better as the conventional mechanisms. We have seen that within the four materials [PETG, TPU, ABS, PLA] the PETG is better at handling deformations than all the other materials. The flexibility of PETG helps the hinges to bend to give the required motion and output of a plier. 
Also form the graphs we can observe that as the force increases, stress and total deformation also increases .

But comparing within the four materials for all forces, least deformation and least total stress is shown by PETG this is due to the fact that PETG has emerged as a most appropriate and attractive alternative to ABS and PLA. Some of the qualities that make PETG more reliable advanced filament material than other three are:

1.Excellent layer adhesion

2.Warp resistance

3.Reduced shrinkage

4.Higher density

5.Shows Chemical resistance to both acidic and basic compounds.

6.Shows Flexible nature of printing on glass, acrylic, glass.

As the 3D printing industry is growing, finished prints are pliable and more impact-resistant. In fact, PETG is flexible enough that it is virtually unbreakable and this characteristic makes PETG suitable material for complaint plier as pliers are used repetitively. Also it has Excellent layer of adhesion that converts it into improved surface finishes. It has Low shrinkage it means it is often a good choice for printing larger items.

Hence we can conclude that material properties also shows that PETG is ultimate choice over other three materials for manufacturing of complaint plier majorly due to its flexible nature and low total deformation.

From mathematical calculations and Topological Path model it has been proved that both analyticaly and mathematically Compliant mechanisms are better that Convectional Plier in terms of torque generation and energy conversions from one link to another.

Hence Authors Conclude that Compliant Pliers 3-D printed in PETG are best for use instead of convectional pliers.

\section{ADVANTAGES}

There are several reasons why a compliant mechanism may be considered for use in a particular application. The major reason behind this is the ease of use of compliant mechanisms in certain applications for example the plier we have 3D printed. One advantage of compliant mechanisms is the potential for a reduction in the total number of parts required to manufacture a specific component. The part count is less in compliant mechanism as it is made up of only one part or 2-3 parts in case of pseudo compliant mechanisms. The number of components required for a compliant mechanism are considerably less than for a rigid version of the same mechanism. Compliant mechanisms are relatively easy to manufacture because they can be manufactured from various manufacturing processes. Compliant mechanisms can be manufactured using many methods such as machining, stamping, laser cutting, and 3D printing. In our case we have used $3 \mathrm{D}$ printing which is a little time consuming but an effective method to manufacture compliant mechanisms. Because compliant have fewer parts and simple manufacturing processes, compliant mechanism manufacturing is cheap as compared to normal. The reduction in part count simplifies manufacturing and reduce both the manufacturing and assembly time and cost.

Traditional mechanisms sometimes lose its precision due to backlash error and wear and tear of certain parts. Compliant mechanisms allow precise motion by reducing or eliminating backlash and wear. Rigid-body mechanisms get 
their motion from physical motion between two different parts or links, which can lead to Mechanical wear. This leads to failure of component and changes geometry and movement of the mechanism these kinds of problems can be solved by using compliant mechanisms. As backlash is caused by interconnected links so it can easily be resolved in case of compliant mechanisms. The fact that it can reduce various errors leads it to design of various instruments. Vibration and noise are caused by the turning and sliding joints of rigid-body mechanisms are also reduced in some applications by using compliant mechanisms.

Compliant mechanisms have a smaller number of movable joints, such as pin (turning) and sliding joints. This results in reduction of friction and reduction in need for lubrication. This is very important characteristic for those components which are not easily available and gets wear because of friction. It is very useful in space application as the lubricant evaporates in low gravity environment.

Another advantage of compliant mechanisms is that they can be scaled down easily as they are made up of lesser number of parts. The reduction in the total number of parts and joints offered by compliant mechanisms is a significant advantage in the manufacturing of micro mechanisms. We can also see a significant reduction in weight for the component that is being manufactured in compliant as compared to rigid body. This weight reduction also plays an important role in space parts and in shipping industry.

As we know that energy in complaint mechanisms gets stored in flexible links in the same way as in spring. This stored energy can be easily used to transform energy or use that energy at later time in a different manner.

\section{DISADVANTAGES}

As the material used in complaint mechanisms are mostly flexible which creates restriction in motion and hence no compliant mechanisms can achieve continuous motion that we achieve in rigid body motion.

Also, due this flexible nature the amount of load the mechanism can withstand is limited and force greater than its limit can cause fatigue and eventually the failure of material which is not the case in rigid bossy mechanisms.

As discussed in advantages energy is being stored in mechanism, not all of this energy is released as it is and hence there can be some losses in energy.

Design are made by taking considerations of manufacturing processes which can sometimes lead to premature failures and can ultimately reduce the confidence of consumers. Also, as they are manufactured using 3D printing, so their life span is less as compared to rigid body mechanisms.

During its analysis using any software such as ANSYS, CERO software is unable to recreate the motion exactly that is been made by the mechanism. This further leads to incorrect analysis of mechanisms. Because if fatigue or stress analysis is wrong in initial stages that can lead to wrong material choice for the mechanism as well as can reduce the life span of mechanism.

As the manufacturing requires 3-D printing so it increases the amount of product being manufactured and hence cost of manufacturing sometime becomes high.

Selection of material that from which our mechanism should be made is sometimes very difficult what happens is sometimes we don't get material that are exactly required by and matches with the characteristics of product.so selection of material is tiresome job. 
Strength of the material, though they will work perfectly only within the given working parameters.

Flexible links cannot achieve 180-degree angular rotation with same precision as rigid linkages, but still can be achieved with better designing.

\section{ACKNOWLEDGMENT}

The objective of this project is to provide clear and thorough presentation of theory and practical knowledge of Compliant Mechanism. To achieve this objective, the group members by no means have worked alone as these ideas have been shaped by comments, suggestions and acceptance given by Prof A.R Mujumdar( Department of Mechanical Engineering).We are thankful to Prof A.R Mujumdar for his guidance, support and inputs in this course project without which it wouldn't have been a success. We are thankful to Prof (Dr) MANGESH CHAUDHARI Head of Department Mechanical Engineering for his support and for addition of such kind of projects in our curriculum. We express our sincere thanks to the management of Vishwakarma Institute of Technology, Pune for allowing us to carry out such educational projects.We express our feelings and respect towards our parents, without their blessings, help and motivation this project could not have been completed and would have been just a dream for us. We are thankful to all those whom we might have inadvertently failed to mention here but have a positive contribution in successful completion of this project.

8.

\section{REFERENCES}

1. I.Her,A.Midha, "A Compliance Number Concept For Compliant Mechanism, And Type Synthesis".

2. https://www.compliantmechanisms.byu.edu/

3. https://www.youtube.com/watch?v=97t7Xj_iBvO

4. Veritasium (Derek Muller)

5. Compliant Mechanisms by - Prof. Larry Howell, Engineering, Brigham Young University

6. Handbook of Complaint Mechanisms by - Calvin C. Chiel

7. Topolology optimization of Complaint Mechanisms by - Benliang Zhu and Xianmin Zhang

8. Engin Tanik,Volkan Parlaktas, "A new type of compliant spatial four-bar (RSSR) mechanism", Mechanism and Machine Theory 46,593-606, (2011).

9. Ashok Midha, Larry L.Howell, Tony W.Norton, "Limit Positions of Compliant Mechanism using the pseudo rigid-body model concept”, Mechanism and Machine Theory 35,99-115 (2000). 